\title{
Tiempos precarios: trabajo y muerte. La crisis del sueño europeo en el cine de Robin Campillo
}

\section{Precarity times: work and death. European's dream crisis in Robin Campillo's films}

\author{
Lucas Martinelli \\ Universidad de Buenos Aires / CONICET, Argentina \\ lucasmartinelli87@gmail.com
}

\begin{abstract}
Resumen:
Los usos de la temporalidad del cine de Robin Campillo ponen en escena un tipo de precariedad producido desde un lapso condensado en las figuras del trabajo y la muerte. Las películas de este cineasta cristalizan escenas que engendran una deformación de la promesa de inclusión social y ponen en evidencia la "crisis del sueño europeo". Estos desplazamientos recuperan la subjetividad de los migrantes, los ancianos, los enfermos, los homosexuales como aquellos sujetos que permiten imaginar ficciones comunitarias e iluminan zonas poco exploradas por las producciones mainstream del capitalismo contemporáneo. Articuladas con la noción de fin del sueño, generan fugas simbólicas por medio del uso de representaciones que constituyen un horizonte político opuesto a la amenaza de los movimientos de extrema derecha y dan cuenta de Europa como continente de desplazamientos migrantes. Los procedimientos de estos filmes generan imágenes políticas que producen un llamado a despertar.
\end{abstract}

\begin{abstract}
:
The use of temporality in Campillo's cinema shapes a kind of precarity build from an impasse condense in the figures of work and death. Campillo's films crystallize situations that engender a deformation of the promise of social inclusion and raise awareness on the "crisis of the European dream". This strategy rescues the subjectivity of migrants, old, sick, and homosexuals as enablers of an ideal, imaginary community while at the same time shedding light on rarely questioned issues in mainstream productions of contemporary capitalism. Along with the notion of "end of dream", it generates symbolic escapes though the use of representations of a politic horizon in clear contrast with the threat posed by extreme right movements; it portrays Europe as a continent of migrants and generates political images as a wake-up call.
\end{abstract}

Palabras clave: precariedad; Robin Campillo; temporalidad; trabajo; muerte; crisis europea.

Keywords: Precarity; Robin Campillo; Temporality; Work; Death; European's crisis. 


\section{Introducción}

El objetivo de este artículo es componer un análisis cinematográfico de las películas de Robin Campillo para considerar el modo en que desde su elaboración de la temporalidad formal y representacional ponen en escena una propuesta estética que, en la construcción de un imaginario europeo, alerta frente a amenazas como la extrema derecha, la xenofobia y los movimientos nacionalistas. Es decir que este trabajo se centra en los aspectos argumentales y narratológicos que construyen sus películas y, en algunos casos específicos y pertinentes, la descripción de las imágenes para ponerlas en relación con indagaciones teóricas de la filosofía y los estudios visuales sobre la precariedad y el tiempo.

Algunas escenas del capitalismo contemporáneo que el cine de Robin Campillo elabora constituyen modos de observar la "crisis del sueño europe $^{1}{ }^{\prime \prime}$. La representación del trabajo y la muerte son formas de ver lo esperable de una vida y dan relieve tanto a la precariedad económica como de la que resulta a partir de una estructura afectiva en cuestionamiento. En definitiva, los motivos sobre los que Campillo elabora su imaginario colocan a los cuerpos en un estado intermedio que no se define por un polo, sino que permite vislumbrar la indeterminación sensorial como un espacio de tránsito no definitivo y en ese enclave, signado por la vulnerabilidad y la ambigüedad, reside lo esencial de su cine: personajes que atraviesan fronteras nacionales, etarias, sexuales y vinculadas a la salud/enfermedad.

En este sentido, este artículo propone un estudio inicial y comparativo de las películas de Campillo, principalmente como realizador integral, pero también en las que ha colaborado. Sin pretender una exhaustividad de reconocimiento sobre la especificidad de su trabajo, sino con la intensión de exponer las relaciones que las ideas del cine en el que ha colaborado pueden establecer con ideas provenientes del ámbito de la teoría.

\footnotetext{
1 Este tema es interpretado en el sentido de cómo las películas pueden proponer problemáticas ligadas al asunto de un modo trasversal en el que elaboran perspectivas sintomáticas sobre ellos. No como reflejo, sino como punto de fuga y alternativa para un estado del mundo real. Una figura que sirve de ejemplo para pensar el estado actual de Europa, pero que es trasladable a todas las sociedades donde el capitalismo instaura los modos de vida.
} 


\section{Tiempos precarios}

Judith Butler (2010) ha referido a la vida del cuerpo como la manera en la que se efectúa un tipo de precariedad, ya que el ser del cuerpo corresponde a un modelado y una forma social, la ontología del cuerpo es una ontología social. En este sentido, la precariedad es una forma de lo social que se puede ver reflejada en cada cuerpo, porque el cuerpo es inminentemente social. De este modo, existiría cierta separación jerárquica entre zonas que pueden indicar el lugar que ocupa un cuerpo y distinguir entre "vidas precarias", vidas de menos importancia y desechables, y "vidas dignas de duelo", valorables, pasibles de ser lloradas, como dos nociones productivas de los mecanismos del poder. Butler (2006) explica que la precariedad se vuelve una condición para el ser (de la vida, del cuerpo o de la comunidad), ya que determinadas formas de distribución del reparto de la vida humana permiten que algunas poblaciones se encuentren más expuestas que otras a una violencia arbitraria. La cuestión de la repartición conduce a las implicancias éticas de los marcos estéticos cuando tienen como objeto los contornos culturales de lo humano. Los marcos de las imágenes pueden quitarnos la sensibilidad frente al sufrimiento y a determinadas muertes y, de este modo, proponer límites sobre el tipo de pérdidas que es posible considerar como tales y llegar hasta a definir la posibilidad misma de considerar si una pérdida es humana o no.

Es posible pensar el flujo temporal sobre el que Campillo construye una interpelación de lo político como registro de la "crisis del sueño europeo" y una exposición de la precariedad en tanto vulnerabilidad subrayada por escenas y personajes, ya que el uso de la temporalidad hace emerger síntomas de una problemática social. En este sentido, es posible retomar el concepto de impasse que Lauren Berlant (2011, p. 192) ha definido como un trecho de tiempo particular, en el cual aspirar a la movilidad prometida por el sueño del capitalismo (un sueño de inclusión social por medio del consumo y el confort) se vuelve una imposibilidad. La temporalidad vacilante descubre al mundo de manera intensa, presente y enigmática. En un mundo marcado por los ritmos de producción del capitalismo, el impasse se vive como un ajuste, una medición o una adaptación que provoca confusión, 
ansiedad, inseguridad. El presente se vuelve un período de tiempo percibido como un callejón sin salida. Esta "crisis del sueño europeo" a la que se hace referencia puede también ser interpretada como el "fin del sueño del capitalismo tardío" (Crary, 2015, p. 41). Este término busca comprender una contemporaneidad en la que los dispositivos de producción de lo visual delinean un horizonte homogeneizador, en el cual no habría rincón del mundo que no resulte penetrado por el tiempo del mercado. Ni siquiera aquello que parece estar ligado a lo más íntimo del ser humano: los sueños.

Jonathan Crary (2015) propone que el lema 24/7 anuncia un tiempo sin tiempo, extraído de cualquier demarcación material o identificable, un tiempo sin secuencia o repetición, en continuidad con el análisis de Gilles Deleuze (1991) sobre las sociedades de control que se caracterizan por la desaparición de brechas, espacios y tiempos abiertos. Para nuestro presente, el sueño podría representar la durabilidad de lo social y en este sentido asemejarse a los umbrales desde los cuales la sociedad se defiende o protege a sí misma, como el estado más privado, vulnerable y común a todos. En este sentido, en la contemporaneidad la producción masiva de imágenes tendería a construir una temporalidad que, en su afán de conservación, colabora con una "amnesia", un tipo de insuficiencia en la cual el tiempo del presente se ensancha e imposibilita la imaginación de tiempos futuros. En este sentido, el tiempo del capitalismo se vuelve totalizante e inhabilita la capacidad de imaginar posibilidades emancipadoras para la desigualdad global instaurada por un modelo de estas características.

En la poética de Campillo como director, montajista y guionista es posible ver los destellos de cierto lapso, una interrupción del sueño del capitalismo global que marca zonas de digresión. La precariedad en relación con el tiempo tiene sus puntos de mayor evidencia en lo laboral y en la muerte, cuando la materialidad de los cuerpos se torna vulnerabilidad y finitud. Una exposición de los límites de la vida que se vuelven relieves de humanidad. 


\section{Tiempo de trabajo}

La figura del trabajo ha sido un motivo privilegiado para acceder a una producción estética sobre lo político porque permite dar notoriedad a las cuestiones concernientes a la opresión, la injusticia y la inequidad. En las relaciones laborales se forjan diferencias entre las clases sociales de un modo muy particular y el cine se ha encargado de observarlas ${ }^{2}$. En diferentes períodos de la historia, la condición laboral fue uno de los principales articuladores para inscribir al sujeto dentro de una formación cultural específica y una narrativa de su vida personal. Sin embargo, en la contemporaneidad este aspecto ha cambiado su composición fundamental. Para Jonathan Crary (2015, p. 83) ya no se construyen los eventos subjetivos que dan lugar a la historia de una vida con secuencias referidas a la familia, el trabajo y las relaciones, sino que el hilo conductor de una historia de vida se constituye con productos electrónicos y servicios mediáticos que filtran, graban y construyen toda experiencia. Al desvanecerse la posibilidad de un puesto de trabajo para toda la vida, la vida posible es la elaboración de un vínculo con los aparatos. Lo que se había considerado personal, se reconfigura para facilitar un revoltijo de identidades, efecto de los dispositivos tecnológicos.

Dos filmes de Laurent Cantet, Recursos humanos (Ressources humaines, 1999) (montado por Robin Campillo) y El empleo del tiempo ( $L^{\prime}$ emploi du temps, 2001) (con su participación en el guion) fueron tomados por Lauren Berlant (2011, p. 191) para ser pensados como estéticas de la puesta en acto del impacto del neoliberalismo en el cotidiano. Dentro de un estudio amplio, en el que considera la noción de "optimismo cruel" sobre la disolución de escenarios optimistas mantenidos en la fantasía de una "buena vida”, Berlant (2011, p. 11) arriba a la idea de Cine de la precariedad como una modulación específica y nueva del realismo francés en el que los cuerpos se desempeñan afectivamente para investigar nuevas condiciones potenciales de solidaridad

\footnotetext{
2 Es posible mencionar dos primeros cortometrajes documentales en los que Campillo colaboró: Les 18 du 57, Boulevard de Strasbourg (2014) sobre una huelga de trabajadores en París y On bosse ici! On vit ici! On reste ici (2010) que muestra retratos de grupos de trabajadores en medio de una demanda social, ambos fueron realizados por el Collectif des Cinéastes Pour les Sans-Papiers.
} 
y emergen de sujetos sin identidades históricas marcadas o ubicaciones sociales similares, pero con condiciones de ajuste que sufren por igual. La contemporaneidad genera una nueva clase global cuya precariedad, como una condición de dependencia y flexibilidad, atraviesa las estructuras y las experiencias de las clases sociales. En este sentido el término "precariado" se vincula con cierta clase trabajadora que tiene subempleos part-time, muchas veces volcados al arte y vinculada con ciertos consumos urbanos. En estas dos películas resuena el ajuste global en la Europa contemporánea y en Estados Unidos sin ser, desde la perspectiva de Berlant, analíticas o polémicas con la fantasía de la "buena vida" global y construyen una estética de tramas político-afectivas.

En la representación de los tiempos del trabajo en ambas películas hay un germen de Campillo como director La primera película, Ressources humaines cuenta la historia de Franck (Jalil Lespert) un estudiante que vuelve de París a la casa de sus padres para hacer una pasantía en una fábrica en la que su padre ha trabajado como obrero durante treinta años. La tarea de Franck en el Departamento de Recursos humanos es la supervisión de las negociaciones para la reducción de la jornada laboral. Sus relaciones se vuelven diferenciales. Por un lado, mantiene cierta distancia con los empresarios de la fábrica por pertenecer a otra clase social, no se puede juntar con los amigos de su padre por trabajar en otro sector de mayor jerarquía dentro de la fábrica y en su cotidianeidad se generan peleas con sus antiguos amigos por haber estado estudiando en París, lo que le daría cierta distinción frente a ellos que se pasaron esos años en el pueblo. Un día por casualidad, Frank descubre que su pasantía sirve para ocultar el despido de doce personas de la fábrica entre los que se encuentra su padre, cerca de ser jubilado. A partir de allí, Frank se enemista con su padre (que por el éxito profesional de su hijo pretende que no deje de formar parte del sector empresarial) y se asocia a una huelga que causa estragos en la continuidad productiva de la fábrica.

Los temas relacionados al trabajo y las diferencias entre las clases sociales se reiteran de diversos modos. La cuestión de las 35 horas semanales, una discusión sobre la solidaridad, el quitar las horas extras y la falsa propuesta 
de trabajar menos y ganar más se complementan con los intercambios de Frank. En el almuerzo de la fábrica conversa con los ejecutivos que le cuentan sus vacaciones en las que practican sky o al encontrarse con sus amigos lo ven diferente por haber estudiado en París, pequeños desfasajes que dan cuenta de fricciones entre situaciones materiales. El núcleo del relato lo constituye la relación íntima y privada de padre e hijo y las diferencias entre sí que funcionarían como representaciones de ubicaciones sociales que resultan antinómicas.

La escena de mayor dramatismo, que funciona como clímax, confronta padre e hijo. A partir de un montaje entrecortado se genera un crescendo en la escena que otorga también cierta perspectiva documentalista sobre lo que se construye. Con pequeños reencuadres de montaje que dan lugar a saltos en el tiempo (jump cuts), la cámara en mano toma registro de un acontecimiento que simula ser real y, de este modo, resultara permeado con la inmediatez de lo que se filmó, como si se tratara de un evento intempestivo cuya fuerza y sensibilidad ha perdurado en el aspecto sucio y descuidado del montaje. La discusión versa en la decisión del padre de continuar su trabajo con la máquina y el pedido de su hijo -correspondiente a la agrupación sindicalpara que se detenga y adhiera a la huelga. Frank, le dice a su padre (que no tiene nombre en la historia) que consiguió su éxito personal, ya que su hijo está del lado de los jefes. Gracias a eso tendrá poder, pero para él eso no es nada en comparación con la vergüenza que le da ser el hijo de un obrero que está en contra de los intereses de su propia clase (al no detener la máquina de trabajo). Más allá de la noción del orgullo, lo que se pone en escena está ligado a la vergüenza. Franck llega hasta la proyección que ha tenido su padre, pero, sin embargo, lo hace como deseo incumplido del otro, no desde su propio deseo. Lo que adquiere no es importante para él, porque tiene otro tipo de construcción identitaria, desde otro tipo de redes de pertenencia vincular. El cumplimiento con lo que dicta con el sistema se transforma en una carga que confronta padre e hijo. Didier Eribon (2015, p. 10) hace una construcción sobre el término de hontoanálisis referido a la culpa que se siente por cierta pertenencia a una clase social que funciona muy bien en este 
sentido, para considerar lo vergonzante como un modo de instalar un tema que refiere al poder y las diferencias sociales que implica el capitalismo.

L'Emploi du temp (2001) es una película que transita de manera constante por sensaciones subjetivas y ambientes plagados de neblinas y vidrios empañados. De este modo, compartiendo el punto de vista focalizado en Vincent (Aurélien Recoing), la información se va descubriendo en la medida que distintas escenas exponen aquello que él oculta a su familia: ha sido despedido de su trabajo y no parece tener en el horizonte una posibilidad concreta para recuperar su posición de asalariado activo. Por lo tanto, el personaje transcurre días fuera de su casa, deambula con su auto, busca lugar en empresas sin conseguir ser parte de las mismas y le dice a su familia que se tratan de reuniones de trabajo. Entre algunas de las tramas basadas en las simulaciones que Vicent construye se puede destacar que pide un préstamo a su padre, intenta incorporar a sus antiguos amigos a un negocio de los cuales recaudaría ganancia por los intereses y se une a un importador de productos falsos que revende como si fueran de primera calidad. Esta incertidumbre desencadena también escenas de conflicto latente con su esposa y el mayor de sus hijos.

En las relaciones de Vincent con los demás Laurent Berlant (2015, p. 196) observa que la globalización hace política y económicamente imaginable aquello que se vive en la intimidad del celular: el contorno de una vida posnormativa en la cual la vivencia es la multiplicación de normatividades que han surgido orgánicamente de las relaciones, no desde instituciones disciplinarias u opresivas en el sentido tradicional. Este tipo de vínculos son fomentados en contextos neoliberales en los cuales antes que relaciones institucionales formadas a largo plazo se privilegian tratos episódicos basados en responsabilidades limitadas y aspectos meritocráticos. Así como la pregunta retórica y, por lo tanto, sin respuesta que Berlant señala en los diálogos del comienzo de Recursos humanos: ¿dónde está tu lugar? (en referencia a las estructuras precarias del mundo laboral y el mundo personal) aparece también con una conversación matrimonial en la cual la esposa de Vincent le habla con franqueza respecto al envejecimiento de su cuerpo. Ambas indagaciones expresarían la precariedad universal del momento 
neoliberal. Se trata de preguntas retóricas en transición abierta al potencial político y existencial, que dan cuenta de la ruptura de las instituciones seguras de la modernidad -como el estado, las corporaciones, la familia y los públicos liberales-. Los protagonistas de ambas películas viven el impasse sin una imaginación que pueda recurrir a los términos y el registro de cómo pueden ser hechos nuevos llamados a construir recursos sociales de reciprocidad.

La cuestión del tiempo es el centro de este filme que parece sostener que nuestro tiempo es lo que dejamos en el trabajo y de este modo, el trabajo es lo que constituye el sostén de nuestra vida. Cuando se pierde un trabajo en el que se ha permanecido durante diez años, la inercia de lo que constituye la cotidianeidad solo puede seguir un rumbo repetitivo en un círculo que gira sobre sí mismo. De este modo, el tiempo transita por zonas grises, desde una inmersión a un estado emocional nómade fluctuante y poco cambiante que, sin embargo, sostiene su impasibilidad y tranquilidad. Se trata de una experiencia narrativa de deriva permanente sobre una atmósfera de indeterminación. Cuando parecen consolidarse determinados nudos ligados a la trampa, la estafa a sus amigos o la empresa con el importador de relojes falsos, eso también se disuelve.

La temporalidad funciona como una dilación constante a lo largo del relato, a la manera de una expansión de la sensorialidad. La durabilidad de los planos se extiende para funcionar del mismo modo que la incertidumbre de Vincent ante el mundo que se despliega frente a él. La escena que se destaca comienza cuando Vincent accede a un edificio vidriado siguiendo el ritmo de otros personajes que son ejecutivos de la empresa. Él se entremezcla entre ellos y pasa desapercibido. Sube en el ascensor y una subjetiva de su mirada repone los pasillos internos en los cuales diferentes personas trabajan en sus oficinas. Miran papeles, hacen llamados. Recorren los espacios a partir de un tránsito distendido hasta que llega a escuchar una reunión en la que se discute la necesidad de estabilidad social de un mercado para invertir en él. El personaje se aleja sin interesarse y se sienta en un sillón (F1). Lee una revista con un gráfico de barras sobre las ayudas de los últimos años brindadas en África. Vincent habla por teléfono con su esposa y un guardia se 
acerca a preguntarle si trabaja allí o tiene cita con alguien. Ante ambas negativas, Vincent se retira cordialmente y el plano deja ver el pasillo de una empresa vacío. El plano siguiente es uno subjetivo de él que conduce un auto por una ruta (F2). En esta simple articulación de la escena entre Vincent y el guardia se pone en evidencia el constante aparentar. Todo el tiempo Vincent simula estar en el trabajo, hacer redes, contactos y negocios, pero sin embargo hay un desfase entre la superficie de su accionar y las capas de mentiras que articula. Esas capas componen un aspecto diferencial frente a lo que sucede, las tramas de Vincent no son reales, se acumulan como falsedades que sólo ocupan un desarrollo temporal. No se trata de un filme que se preocupe de lo verdadero y lo falso, sino principalmente sobre los modos del transcurrir en actividad, hacer algo puede ser simplemente conducir en una ruta o esperar en una sala, aunque no haya ninguna reunión a la que asistir. Trabajo y tiempo se convierten en modos de exponer que la durabilidad de la experiencia y es el modo de ser de la precariedad del sujeto. Cuando estos elementos se conjugan en un contexto neoliberal permiten observar la emergencia de los momentos de crisis como aspectos que refieren a procesos sociales, antes que a la individualidad. Jean-Michel (Serge Livrozet), el personaje que lo inicia en el negocio de la estafa para vender relojes falsos, le pregunta que hará cuando su familia se entere de la mentira. Él responde que sabe que no durará mucho, pero al menos le permite "ganar tiempo".
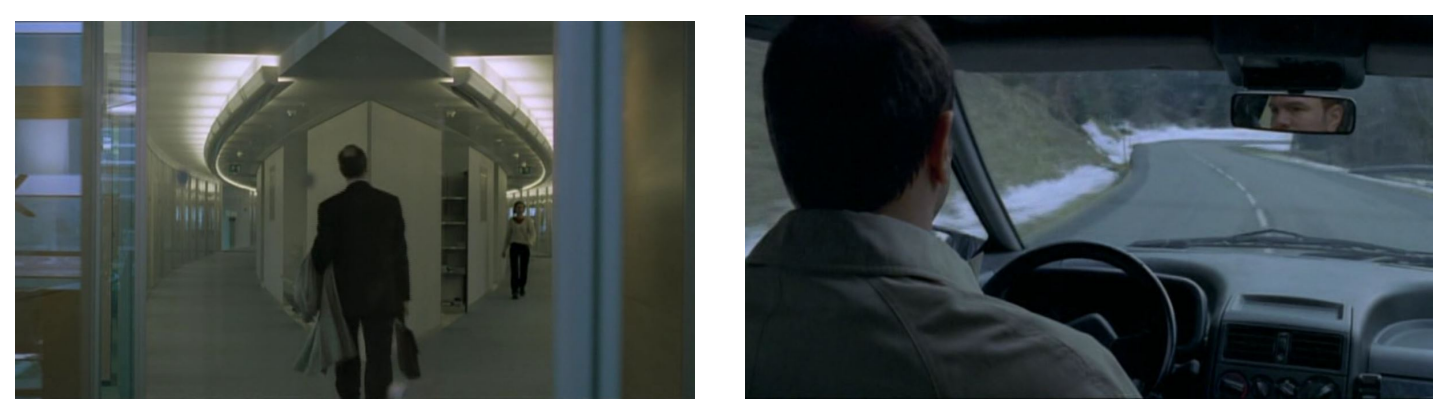

F1 y F2 
Otras dos películas dirigidas por Laurent Cantet3, guionizadas y montadas por Campillo, ponen el acento en situaciones ligadas a lo laboral y las circunscripciones de la jornada de trabajo con el agregado de tematizar los tiempos dictados por los procesos educativos. Entre les murs (2008) y Taller Literario ( $L$ 'atelier, 2017) elaboran de diferentes modos el tiempo elaborado por el trabajo del aula y se preguntan por el aspecto potencial que tienen para producir transformaciones en el campo social.

\section{Tiempo de muerte}

La segunda figuración de la temporalidad en el cine de Robin Campillo es la muerte. La muerte no solo como un final para la vida, sino como un contorno en que la importancia de la vida cobra relieve. A partir de la exposición, la vulnerabilidad y la proximidad con la muerte a la que un cuerpo en su contexto social es arrojada, se construye un determinado tipo de precariedad en su sentido relacional y gubernamental.

El tiempo de la muerte se representa en Campillo desde tres posibilidades. En primer lugar, una intermitencia. La muerte es una estela que provoca una recuperación de menor luminosidad sobre la superficie de la vida, es decir, como una repetición de menor injerencia que la vida. El tiempo como ausencia y huella de la materia. En segundo lugar, la expansión del tiempo opera directamente en un proceso de desmaterialización. La pérdida de la materialidad constituye un goce placentero ligado a la sexualidad que se produce desde la intensidad de la disolución. En tercer lugar, la muerte como elaboración del evento mortuorio y la implicancia material (económica, performática y anímica) que acarrea el tiempo cuando se vincula a la materia. La película Les revenants (2004) imagina lo que pasaría si los muertos de los últimos diez años, en especial los ancianos, volvieran a la vida. 4 Con planos

\footnotetext{
3 Por una cuestión de extensión, este artículo no puede ahondar en otras cintas de Laurent Cantet como editor Les sanguinaires (1997), Foxfire (2012), Regreso a Ítaca (Retour à Ithaque, 2014) o co-guionista Foxfire que poseen elementos que se vinculan a los que se elaboran aquí.

4 Esta película ha dado lugar a una serie televisiva homónima dirigida por el mismo director en la cual se extienden algunas de las escenas que contiene.
} 
que muestran a grupos enormes de muertos revividos que caminan por la calle, hace pensar en el lugar de la administración de las poblaciones. La pregunta que atraviesa el filme es qué hacer, cuando vuelven a ingresar a la ciudad, con todos esos cuerpos que no se tenían en cuenta. No se conocen las causas que producen que los muertos vuelvan. Pero vuelven con una vida diferente que no es la misma que mantenían antes, sino que se volvió vegetativa y deambulante. Los que volvieron pretenden dormir, pero en realidad están despiertos. El modo de atenuar su actividad constante y lenta que parece ser peligrosa es por medio de una droga que los mantiene en calma. Sin saber muy bien cómo, pueden conspirar o planear un sabotaje. Esta situación genera un intento de control que pone en escena todo lo que tiene que ver con cierto reclutamiento, se moviliza el ejército y se ve el armado constante de camas, se trata del intento de subsumir esas masas de cuerpos en letargo a un orden. De este modo, estos muertos revividos pueden funcionar como una metáfora del envejecimiento social de Francia o directamente de los migrantes como aquellos que por fuera del planeamiento urbano vendrían a ocupar las calles. Estos nuevos integrantes parecen molestar porque no se pueden adaptar y en esa inadecuación, que está subrayada por el aspecto musical, reside lo siniestro de la película.

El filme se inicia con planos descriptivos de la circulación de los muertos revividos en la ciudad (F3). Se trata de planos contemplativos del desplazamiento lento de los cuerpos que aparecen al comienzo de la película, en algunos momentos del desarrollo y en el final. Instauran un tiempo de circulación urbano de estos cuerpos que los aproxima a una sensación de movimiento como un itinerario migracional. Se menciona que los "revividos" tienen reuniones regulares o por intervalos. No se sabe si siempre conversan con los mismos. No volvieron a la vida con la plenitud de su humanidad. Es decir, se convierten en encarnaciones de cierta otredad nómade que circula por las ciudades. Este aspecto reforzado por las cámaras en mano propone la idea del sabotaje en la ciudad y la necesidad del despliegue de un saber que

Por otro lado, una de las novelas publicada un año después es As Intermitências da Morte (2005) de José Saramago. En ella se muestra un país en el que un día la gente deja de morir y a partir de allí desencadena una serie de implicancias materiales relacionadas con esta cuestión. 
entrecruza lo bélico y lo químico. Por cámaras infrarrojas, la mirada del espectador se adhiere a la de un ejército que vigila, está expectante de los movimientos que parecen planificados, pero que sin embargo escapan a una comprensión racional. El motivo de las cámaras de vigilancia se vuelve uno de los recursos reiterados en el filme. Las cámaras térmicas, generan la confusión de cómo entender la vida de esos cuerpos que se movilizan en estado de indeterminación.

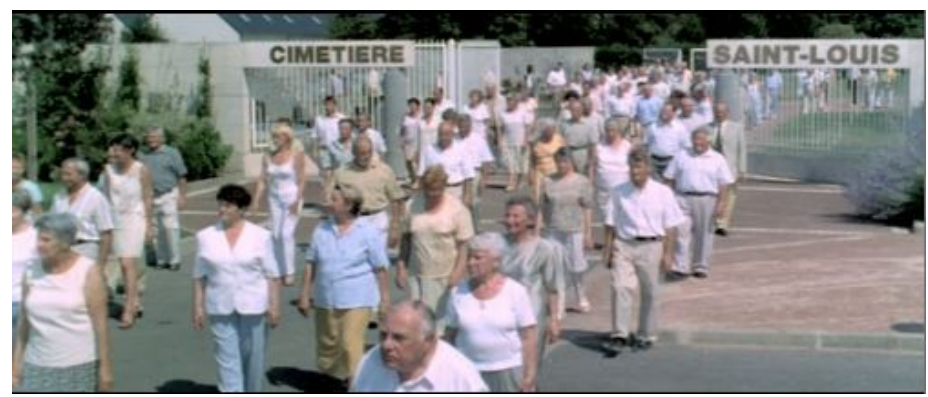

F3

El modo en que se accede a las historias es a partir de cada uno de los vínculos familiares que dan acogida a los lazos que habían muerto. Se trata de padres, abuelas, esposos, hijos, lazos de familia que se recomponen de una manera extraña. Ninguno de los seres a los que se les da hospitalidad rehacen los modos de vida que tenían antes de partir y eso va dejando rastros de una familiaridad desencastrada y deforme.

En el final, una de las mujeres que ha sufrido con las peripecias de la vuelta de su marido, luego de bañarse frente al espejo, saca con la mano el vapor empañado del espejo. Con este gesto parece indicar que todo ha sido una pesadilla. Aunque el relato no se incline por la idea de la falsedad de lo ocurrido, deja en un estado de indeterminación y tensión que contribuye con el impasse temporal que implica la vuelta de esos seres que temporalmente han dejado de lado la muerte. El tiempo de la vuelta, que constituye el tiempo narrativo representado, es en sí mismo un estado diferencial del cotidiano que marca un espacio especial y diferente en la vida de los afectados. Un tiempo que se constituye como lapsus y repetición del estado de duelo. Una temporalidad que aparece como intermitencia de la vida en su otra cara de la muerte. 
Por otro lado, en esa misma línea de la temporalidad de la muerte como intermitencia de la vida, se erige la espectral Planetarium (Rebecca Zlotowski, 2016) en la que Robin Campillo hizo el guion y el montaje5. La historia que se cuenta es la de Laura (Natalie Portman) y Kate Barlow (LilyRose Depp) dos hermanas norteamericanas que se comunican con los muertos. En una gira por Europa, particularmente en el París de 1943, conocen al productor cinematográfico André Korben (Emmanuel Salinger) que las quiere utilizar para hacer pruebas y filmar fantasmas. Mientras Laura comienza una carrera como actriz, Kate desarrolla sus poderes de médium. Son varias las metáforas que recorren este relato de la vida, pero tal vez uno de los aspectos más interesantes del filme es que al ir al punto del ojo de la serpiente del holocausto no sea el camino que elija trazar. La muerte de los personajes principales se concreta por dos zonas: el cáncer y la llevada a juicio de André donde se le quita su nacionalidad francesa y se lo condena por su pasado judío. Estas dos películas muestran cómo el tiempo puede convertirse en radiografía de la vida.

El aspecto de la temporalidad de la muerte como desmaterialización aparece en Eastern Boys (2013, Robin Campillo). El filme presenta el vínculo entre un hombre de clase media y un muchacho perteneciente a un grupo de inmigrantes del Este que se desempeña como prostituto. Lo particular de la película es que pone de relieve la muerte como la disolución y transformación de un vínculo. Entre los dos personajes, cliente y prostituto, se produce un cambio del intercambio comercial, amoroso y sexual por un vínculo filial también amoroso, de sustento económico, pero no sexual. Ese nuevo modo es a su vez un terreno de acogida y hospitalidad ${ }^{6}$. Este pasaje de vínculo se concreta de modo sutil en un entramado temporal que produce una torsión respecto a lo esperable y marca, con la modificación progresiva de la relación, un ritmo humanitario. El muchacho que aparece por primera vez ligado a

5 Otra figura femenina como la de Stephanie Leger es muy importante en el recorrido de Campillo, ya que actuó como como montadora en: Les sanguinaires, Recursos humanos (Ressources humaines, 1999) L'emploi du temps, Les revenants, La clase (Entre les murs, 20o8), Foxfire y 120 battements par minute.

6 Algunos desarrollos sobre la posibilidad de pensar el modo en que esta película hace aparecer la precariedad fueron realizados por Ianinna Moretti (2019). En este caso, el enfoque que se desarrolla es diferente, a pesar de compartir algunas perspectivas. 
una banda criminal pierde esa característica en una mutación que implica la incorporación a un sistema legal y un circuito de ciudadanía. En este sentido figura a una figuración de Europa como territorio de acogida.

El filme se divide en cuatro apartados. En el primero "Su majestad la calle", Daniel (Olivier Rabourdin) conoce a Marek/ Rouslan (Kirill Emelyanov) en la estación Norte de París. En el segundo, "Esta fiesta de la que soy rehén" es donde aparece una trama de relevancia en el aspecto que liga lo que tiene que ver con la subjetividad y la temporalidad de la fiesta como el proceso de desmaterialización. A Daniel le roban absolutamente todos los objetos muebles que tiene en su casa. Pierde consciencia de lo que está pasando, ya que lo alcoholizan y lo drogan y, en un proceso percibido desde su punto de vista, se puede observar como en la temporalidad de la fiesta de música electrónica, todo aquello que componía lo material de su hogar le es arrebatado. Esta escena en la que pierde todo, en un tiempo indeterminado, está uno de los modos en los que la película entrelaza cierta idea de lo material como desrealización y perdida. En el tercer apartado: "Lo que fabricamos juntos", es donde se elabora el pasaje de un vínculo a otro. En el desarrollo de la relación se da una escena de cotidianeidad en la cual Daniel y Marek compran cosas en un supermercado, aparece el aspecto traumático del pasado de Marek. A partir de las revelaciones de su relato, se cuela la guerra y su orfandad como información que hace a su propia identidad y también por medio de la confesión de su verdadero nombre: "Rouslan". Una identidad que se modifica y a la que Daniel, en principio, le cuesta entender. Con este acercamiento y el pedido de "Rouslan" de la confianza de Daniel (le pregunta como se dice "trust" en francés), el vínculo entre ellos toma otra proximidad en la cual, Daniel decide dejar de tener sexo con él, pero no soltar su vínculo amoroso. El último capítulo "Hotel Halt. Calabozos y dragones" presenta una trama cercana al género policial y de suspenso en el intento de Rouslan de buscar su pasaporte que está en manos del jefe de la banda de los compañeros migrantes. Este cierre apoteótico las fuerzas policiales se ponen a cazar migrantes -como una respuesta justiciera ante la maldad del jefe- y Daniel puede salvar al muchacho. 
El último plano de la película se detiene a la salida del juzgado en el que por medio de su adopción por parte de Daniel se dará la ciudadanía a Rouslan. La cámara avanza por la sala vidriada y se coloca en un lugar en el que se puede observar la calle. En el momento final, por contraposición al comienzo en el cual la calle, la imagen muestra el escenario urbano como un lugar seguro de acogida al extranjero que logra integrarse a la sociedad (F4).

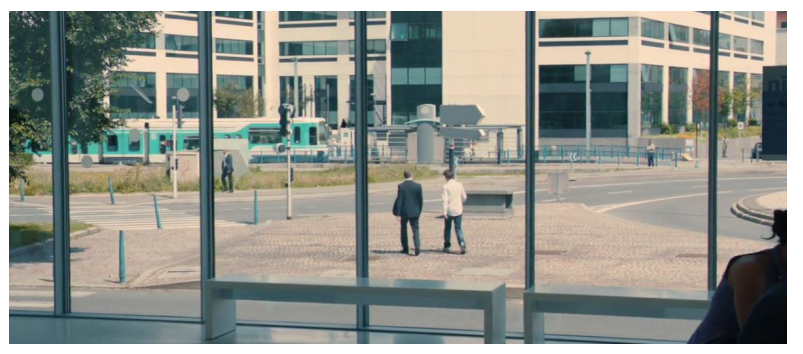

F4.

La temporalidad de la muerte se da también como un registro de la materialidad que implica hacerse cargo de un cuerpo. Bienvenidas al paraíso (Vers le sud, Lauren Cantet, 2005), en la que Campillo trabajó como guionista y montajista, es una película que retrata el erotismo condensado en el turismo sexual de tres norteamericanas en las playas de Puerto Príncipe. Dos de ellas se apasionan y disputan un muchacho negro, Legba (Ménothy Cesar) con el que tienen sexo a cambio de dinero, comida y regalos. En el final del filme, la muerte ocurre como un modo de mostrar una dimensión de la cuestión social. El cuerpo de Ledba aparece arrojado en la playa junto a otra de las mujeres que también se desempeñaba como prostituta. El interés del filme en colocarse no sólo en el punto de vista de las turistas, sino de los nativos se observa en la ambulancia que los lleva (F5) En un ajuste de cuentas que ya se había anunciado, estas muertes son producto de las implicancias mafiosas y las redes de poder institucional. Cuando un policía encargado de investigar sobre los cadáveres indaga, con la ayuda de un trabajador del restaurante que funciona como traductor, sobre relación de Ellen (Charlotte Rampling), una de las protagonistas, con el muchacho ella se preocupa por lo que puede pasar después. El policía le explica que la vida de ningún turista corre peligro en Haití. Esos cuerpos arrojados a la playa muestran la implicancia material que implica un cuerpo y sostienen que las 
diferencias de proximidad a la muerte de cada cuerpo responden también a una distribución racial, de clase y nacional, entre otras.

La película referida directamente a la muerte y la ceremonia material que conlleva el evento mortuorio en su desarrollo temporal es 120 battements par minute (Robin Campillo, 2017). Desde un retrato colectivo del desenvolvimiento de ACT UP París, una organización destinada a generar visibilidad y compromiso estatal respecto a la lucha contra el SIDA, se destaca el trayecto de Sean (Nahuel Pérez Biscayart) que, más allá de la grupalidad en la que está inmerso, funciona como anclaje narrativo. Este personaje con una participación fundamental en las tomas de decisiones y acciones se ve envuelto en un romance con Nathan (Arnaud Valois), otro de los participantes, y en el final del relato muere por complicaciones de salud vinculadas al HIV. La elaboración de la temporalidad en el filme tiene ciertas ramificaciones de mayor complejidad que en los filmes anteriores.

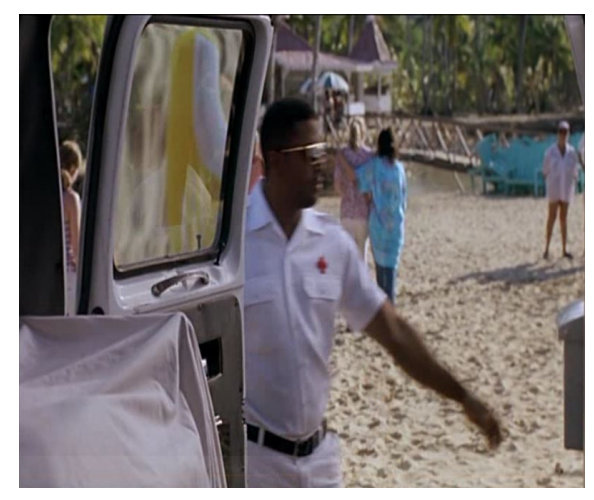

F5

Un primer aspecto trata de la revisión del período histórico del comienzo de los noventa vinculada a la perspectiva del director que participó realmente como activista del grupo. El comienzo del filme ocurre dentro de un espacio en el cual se tienen reuniones asamblearias de información y toma de decisiones. Este núcleo los lleva, a partir de sus puestas en común, a los demás lugares que conforman la historia. Se discute sobre la relevancia de un boicot organizado unos días atrás en un congreso médico y, en esa recuperación de lo sucedido, el relato repone los acontecimientos de modo alternado y repetitivo con el presente, para enfatizar determinadas acciones que fueron realizadas y dar relieve a la reflexión. Ese pasado reciente para la 
historia funciona como una especie de ensayo mental, un borrador en la revisión de un período histórico desde los recuerdos personales compartidos por los participantes. Es decir, que el relato recupera a partir de los nexos subjetivos de cada personaje con el pasado un entramado común y en proceso. La repetición de las acciones subraya este esquema y organiza el inicio del relato como una posición sobre la historia reciente compuesta de relaciones subjetivas compartidas7. La música electrónica, colabora con esos tiempos para recuperar el pasado como una repetición y un ritmo netamente físico y corporal.
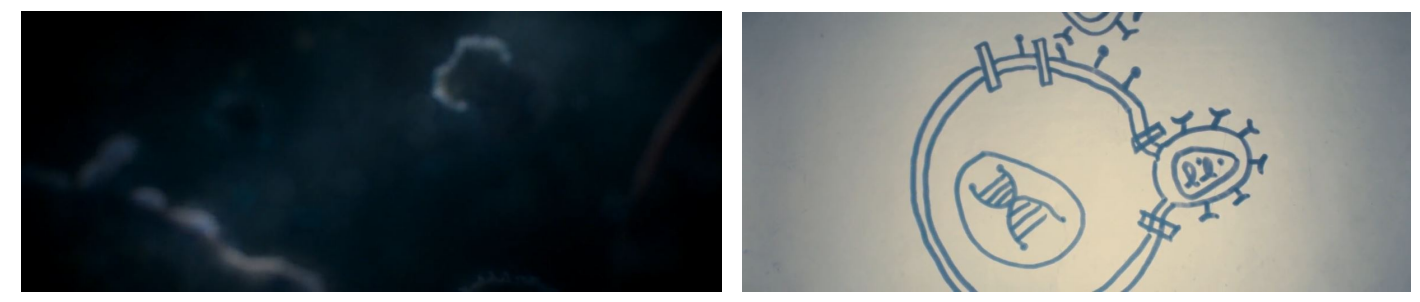

F6 y F7.

Un segundo aspecto que toma relevancia en el desarrollo de la trama está vinculado con la temporalidad en suspensión de la fiesta de música electrónica. Los personajes vuelven de un boicot y, por medio de un montaje alterno, se los muestra dentro de un escenario abstracto, reiterado a lo largo del filme, en el que fragmentados por el cuadro ponen en contacto sus cuerpos, bailan y cruzan miradas. Las luminosidades y las motas de polvo suspendidas en el aire, al estar filtradas por el lente de la cámara, dan la impresión de que el polvo del aire son copos de nieve que flotan y se desplazan en el espacio (F6). Esa primera abstracción se transforma en una estilización digital en la que se puede observar una primera aparición del virus desde un microscopio como una imagen de estudio científico biológico. Esta imagen, que más tarde reaparece, vuelve a transformarse y acompañado de una voz en off que lo explica en una situación de discusión médica se convierte en un esquema dibujado y plano (F7). Esta pequeña articulación de imágenes funciona como acople de lo relativo a la festividad, el encuentro

\footnotetext{
7 De hecho, en el único momento que aparece un flashback como recuerdo subjetivo individual es en una conversación entre Sean y Nathan, donde el primero recuerda la vez que se contagió el virus. Si bien esa escena puede ser una escena compartida por todos lo que atravesaron la escena del contagio resulta estrictamente personal.
} 
que produce la grupalidad, y el interés de explicación científico para el combate contra el virus. Los márgenes temporales y espaciales de la fiesta producen un modo de sensibilidad que desborda sus fronteras y produce nuevas formas para considerar el espacio y el tiempo en común. Más tarde se discutirá en la asamblea sobre la importancia de bailar en la calle como otro de los modos de generar visibilización y adhesión a la causa. Pero en esta primera articulación de dimensiones subjetivas la fiesta y la búsqueda por la causa del virus permiten un nuevo modo de pensar el espacio y el tiempo de lo común como una adherencia a la materia, en este momento a lo estrictamente biológico, corporal, microscópico.

En tercer aspecto, otra de las dimensiones que entrelaza tiempo y materialidad es cuando el filme recurre a las imágenes de archivo para proponer un diálogo entre aquello que muestra la ficción y aquello que ocurrió en la historia y subraya el uso político que tiene un cadáver en el espacio público. Uno de los personajes Jérémie (Ariel Borenstein) remite desde su voz en off al motín revolucionario del 23 de febrero de 1848 que dio lugar a la segunda república francesa. Las imágenes que completan su relato son las del archivo de ACT UP París (una marcha de antorchas, una intervención en una iglesia, un trazado de siluetas en la calle) y las de él mismo ficcional siendo internado de emergencia en el hospital. En esta progresión de imágenes la pregunta instalada es cómo hacer que esos cuerpos, transformados en cuerpos políticos por el abandono estatal frente a la pandemia, puedan extremar la potencia de su intervención en el espacio público. La respuesta tiene que ver con el uso de las cenizas, de los restos biológicos, que pueden tener un efecto de impacto arrojados a las instituciones consideradas responsables de no frenar el avance de la enfermedad.

Por último, las escenas finales vinculadas al evento de la muerte de Sean presentan, desde un estilo realista, una temporalidad en relación con el resto del filme que, sin serlo estrictamente, parece dilatada. Es decir, la preparación para la muerte en su casa se completa con la llegada de todos los personajes que participan del colectivo y el relato se toma su tiempo para mostrar la reacción de cada uno. Antes que sintetizar la situación, le da lugar 
de acontecimiento. La observación de la cámara sobre cada una de las acciones y los personajes vinculados al ritual de la muerte, por parecer una expansión del tiempo resalta la dimensión de evento que contiene la muerte en sí. Le otorgan una superficie especial en la que el tiempo en la que se articulan las llegadas, las reacciones y las nuevas relaciones que se establecen entre los personajes hacen de la temporalidad una expresión condensada del orden material del mundo.

La película termina con las cenizas de los muertos siendo desparramadas sobre un catering de una de las aseguradoras. Esa intervención post mortem se entrecruza por la música y las imágenes con la fiesta y el sexo. La intrusión se superpone en un nivel simbólico con los cuerpos de las marchas que ocuparon las calles. Ante la pregunta por cómo hacer un cuerpo político, parece que la respuesta viene de la sensación en esa suspensión temporal de la fiesta, un impasse, que se materializa y en el evento de la muerte que muestra el camino para contar lo que el cuerpo tiene de precario y de la relación entre la precariedad con el tiempo.

\section{Conclusiones}

A lo largo de este artículo se desarrollaron los modos en los que el cine de Robin Campillo utilizó la temporalidad en sus filmes y produjo determinadas zonas de temporalidad como efecto de una precariedad de la vida que funcionó también como crítica al sistema y dieron relieve a la presencia de la crisis del sueño capitalista en el contexto europeo. Con la utilización de nociones de la narratología, la filosofía política, los estudios visuales y la teoría de los afectos se consideró un entramado de figuras y categorías que recorren todos los filmes de Campillo, pero se construyó un modelo que puede hacerse extensivo para pensar otras cinematografías. En principio la temporalidad ligada al trabajo se pensó como un modo para mostrar el estado injusto del mundo. Y luego, la temporalidad ligada a la muerte se desplegó en tres modulaciones asociadas a sus películas, donde la intermitencia, la desmaterialización y la realización del tiempo como implicancia material, generaron relatos que dieron cuenta de atmósferas que, 
por medio de su apreciación crítica y percepción sensorial, el espectador necesariamente está llamado a considerar. Las diferentes figuraciones sobre un estado crítico del mundo, ligado a sus implicancias materiales, generan puntos de inflexión en los cuales ciertos relatos sobre la vida se vuelven modos de denunciar un estado problemático europeo y una necesidad de pensar nuevos modos para encontrarse con el mundo fuera de la pantalla.

\section{Referencias bibliográficas}

Berlant, L. (2011) Cruel Optimism. Duke Univesity Press: USA.

Butler, J. (2006). Vida precaria. El poder del duelo y la violencia. Buenos Aires: Paidós.

Butler, J. (2010). Marcos de guerra: las vidas lloradas. Buenos Aires: Paidós.

Crary, J. (2015). 24/7. El capitalismo tardío y el fin del sueño. Buenos Aires: Paidós.

Deleuze, G. (1991) Posdata sobre las sociedades de control. En Christian Ferrer (Comp.) El lenguaje literario, t.2. Montevideo: Nordan.

Eribon, D. (2015). Regreso a Reims. Buenos Aires: Libros del Zorzal.

Moretti, I. (2019). Muchachos del Este: boceto para des-ordenar los afectos. En Sentirse precari*s. Afectos, emociones y gobierno de los cuerpos. Córdoba: Editorial de la UNC.

\section{Filmografía citada}

Campillo, R. (2004). Les Revenants. Francia: Haut et Court.

Campillo, R. (2013). Eastern Boys. Francia: Les Films de Pierre.

Campillo, R. (2017). 120 battements par minute. Francia: Les Films de Pierre.

Cantet L. (1997). Les sanguinaires. Francia: Arte France Cinéma, Haut et Court.

Cantet L. (2012). Foxfire. Francia: Haut et Court, Memento Films International, The Film Farm, France 2 Cinema, Lorette Distribution, France Télévision, Canal+, Ciné+.

Cantet L. (2014). Retour à Ithaque. Francia: Borsalino Productions.

Cantet, L. (1999). Ressources humaines. Francia, Reino Unido: La Sept.

Cantet, L. (2001). L'Emploi du temps. Francia: Haut et Court.

Cantet, L. (2005). Vers le sud. Francia: Haut et Court. 
Cantet, L. (2008). Entre les murs. Francia: Haut et Court.

Cantet, L. (2017). L'Atelier. Francia: Archipel 35, France 2 Cinema, Canal+, Ciné+, Région Provence-Alpes-Côte d'Azur, Soficinéma 13, Procirep, Angoa.

Collectif des Cinéastes Pour les Sans-Papiers. (2010). On bosse ici! On vit ici! On reste ici. Francia: Collectif des Cinéastes Pour les Sans-Papiers.

Collectif des Cinéastes Pour les Sans-Papiers. (2014). Les 18 du 57, Boulevard de Strasbourg. Francia: Collectif des Cinéastes Pour les Sans-Papiers.

Zlotowski, R. (2016). Planetarium. Francia: Les Films Velvet, Les Films Du Fleuve, France 3 Cinéma. 